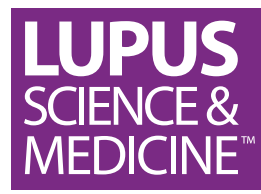

\title{
Unique clinical characteristics, autoantibodies and medication use in Native American patients with systemic lupus erythematosus
}

\author{
Joseph M Kheir, ${ }^{1}$ Carla J Guthridge, ${ }^{1}$ Jonathon R Johnston, ${ }^{1,2}$ Lucas J Adams, ${ }^{1}$ \\ Astrid Rasmussen, ${ }^{1}$ Timothy F Gross, ${ }^{1}$ Melissa E Munroe, ${ }^{1}$ Rebecka L Bourn, ${ }^{1}$ \\ Kathy L Sivils, ${ }^{1}$ Joel M Guthridge, ${ }^{1}$ Michael H Weisman, ${ }^{3}$ Daniel J Wallace, ${ }^{3}$ \\ Juan-Manuel Anaya, ${ }^{4}$ Adriana Rojas Villarraga, ${ }^{5}$ James $\mathrm{N}$ Jarvis, ${ }^{6}$ John B Harley, ${ }^{7,8}$ \\ Judith A James ${ }^{1,9}$
}

To cite: Kheir JM, Guthridge CJ, Johnston JR, et al. Unique clinical characteristics, autoantibodies and medication use in Native American patients with systemic lupus erythematosus. Lupus Science \& Medicine 2018;5:e000247. doi:10.1136/ lupus-2017-000247

- Additional material is published online only. To view please visit the journal online (http://dx.doi.org/10.1136/ lupus-2017-000247).

Received 31 October 2017 Revised 16 January 2018 Accepted 2 February 2018

Check for updates

For numbered affiliations see end of article.

Correspondence to Dr Judith A James; judithjames@omrf.org

\section{ABSTRACT}

Objective Systemic lupus erythematosus (SLE) is a systemic autoimmune disease with varied morbidity and mortality. We assessed clinical presentations, autoantibody specificities and therapeutic interventions in Native American (NA) patients with SLE.

Methods Patients with SLE meeting 1997 American College of Rheumatology classification criteria $(n=3148)$ were enrolled between 1992 and 2010 in the multiethnic, cross-sectional Lupus Family Registry and Repository. Clinical, demographic and therapeutic information were extracted from medical records using a standardised form and formalised training. Autoantibodies were assessed by indirect immunofluorescence (antinuclear antibodies (ANA) and antidouble-stranded DNA), precipitin (ENA) and ELISA (IgG and IgM anticardiolipins).

Results NA patients met SLE classification at a younger age $(29.89 \pm 12.3$ years) than European Americans (EA; $32.02 \pm 12.87, P=0.0157)$ and a similar age to AfricanAmericans (AAs) and Hispanics (HIS). More NA patients had concurrent rheumatic diseases or symptoms, such as Raynaud's phenomenon, interstitial lung disease, Sjögren's syndrome and systemic sclerosis. Compared with EAs, NAs were more likely to have high-titre ANA $(\geq 1: 3240 ; P<0.0001)$ and had more SLE-associated autoantibodies. Autoantibodies with unknown specificities were more common in NAs (41\%) compared with other racial/ethnic groups in this collection (AA: 24\%, $\mathrm{P}=0.0006$; EA: 17\%, $\mathrm{P}<0.0001$; HIS: $23 \%, \mathrm{P}=0.0050)$. Fewer NA patients used hydroxychloroquine (68\%) compared with others (AA: 74\%, $\mathrm{P}=0.0308$; EA: 79\%, $\mathrm{P}=0.0001$, HIS: $77 \%, \mathrm{P}=0.0173$ ); this was influenced by lower hydroxychloroquine use in NA patients from Latin America (32\%). NA patients had higher rates of methotrexate use $(28 \%)$ compared with $\mathrm{AA}(18 \%, \mathrm{P}=0.0006)$ and $\mathrm{HIS}$ patients $(14 \%, \mathrm{P}=0.0003)$, higher azathioprine use $(38 \%)$ compared with EA patients $(30 \%, \mathrm{P}=0.0105)$ and higher mycophenolate mofetil use (26\%) compared with EA (17\%, $\mathrm{P}=0.0012)$ and $\mathrm{HIS}$ patients $(11 \%, \mathrm{P}<0.0001)$.

Conclusions NA patients are diagnosed with SLE earlier in life and present worse concurrent rheumatic disease symptoms than EA patients. NA patients also are more likely to have expanded autoantibody profiles and precipitins of unknown specificities.

\section{INTRODUCTION}

Systemic lupus erythematosus (SLE) is a chronic, systemic autoimmune disease associated with immune dysregulation, varied clinical presentations and diverse patient outcomes. ${ }^{12}$ Classification of SLE is challenging, requiring evidence of organ system involvement and the presence of established disease-associated autoantibody specificities, such as autoantibodies against doublestranded DNA (dsDNA), DNA-and-RNA binding proteins and other nuclear proteins. $^{3-5}$

SLE is more common in females than males $\left(9: 1\right.$, respectively). ${ }^{6}$ In addition, SLE disproportionately affects certain minority and socially marginalised populations with a higher degree of morbidity, earlier mortality and enhanced comorbidities. ${ }^{17}$ For example, North American Indians have a higher prevalence of SLE (up to 1.7 times greater), more damage accrual, higher disease activity scores by the SLE disease activity index ${ }^{8}$ and higher SLE mortality rates than other racial/ethnic groups. ${ }^{9-13}$ In one regional study, the rate of interstitial lung disease and other pulmonary involvement was directly related to the early mortality and increased morbidity rates of Native American patients with SLE. ${ }^{14}$

Native American patients can face persistent disparities in healthcare in part due to high numbers of patients being underinsured and having poor health status, along with other significant barriers to care. ${ }^{1516}$ Even if patients have access to insurance, patients who live in remote, impoverished areas are less likely to receive regular care from specialists. ${ }^{17} 18$ These obstacles translate into less effective disease management and worse outcomes. 
For example, in Oklahoma, Native American patients with rheumatic disease tend to have a higher incidence of SLE and more frequent concurrent autoimmune diseases when compared with other ethnicities. ${ }^{10} 1920 \mathrm{~A}$ select Native American group exhibits a 40-fold increase in the prevalence of systemic sclerosis, ${ }^{19}$ and some Native Americans with rheumatoid arthritis have a higher prevalence of Sjögren's syndrome than patients of other ethnicities. ${ }^{19} 21$

Differences in clinical manifestations of rheumatic diseases together with socioeconomic disparities create unique challenges in diagnosing and treating Native American patients with SLE. In order to better characterise SLE in Native American patients, we have leveraged samples and information contained in the Lupus Family Registry and Repository (LFRR), a large, racially/ethnically diverse cohort of patients with SLE and their unaffected relatives. ${ }^{22}$ The present study compares clinical and demographical features of Native American participants with SLE in the LFRR to those from other racial/ ethnic groups.

\section{METHODS}

\section{Study population and patient samples}

Research was conducted in accordance with the Helsinki Declaration. All LFRR participants provided written informed consent and release of medical record information. Enrolment to the LFRR was open to females and males of any age. All patients with SLE in the LFRR $(n=3148)$ were diagnosed with SLE by a physician and fulfilled $\geq 4$ American College of Rheumatology (ACR) classification criteria for SLE. ${ }^{22-24}$ Concurrent autoimmune disorders in SLE were ascertained by medical record review by trained clinicians. Racial demographics used in this study were self-reported and supported by having at least one family member in the LFRR who self-reported the same race (Native American: $n=268$, African-American: $n=1074$, European American: $n=1567$ and Hispanic: $\mathrm{n}=239$ ). Country of residence was also collected by patient self-reporting with Native Americans representing three regions: continental USA and Puerto Rico ( $\mathrm{n}=190,71 \%)$, Canada $(\mathrm{n}=1,0.3 \%)$ and Latin America (Colombia, British Virgin Islands and Barbados; $\mathrm{n}=72,27 \%)$. The region of five (2\%) individuals was unspecified. Medication usage was determined by medical record review.

\section{Autoantibody assays}

Standardised serological tests were performed in the College of American Pathologists-certified Oklahoma Medical Research Foundation (OMRF) Clinical Immunology Laboratory to assess autoantibodies present at the time of enrolment to the LFRR. Antinuclear autoantibody (ANA) positivity and titre were determined by indirect immunofluorescence (IIF) with HEp-2 cells, and anti-dsDNA by IIF against Crithidia. Antibodies to extractable nuclear antigens (anti-Ro/SSA, La/SSB, Sm, nRNP, ribosomal $\mathrm{P}$ and Jo-1) were detected by precipitin, ${ }^{25}$ and antibodies against unidentified antigens were detected by immunodiffusion. IgM and IgG autoantibody specificities towards anticardiolipin (aCL) were detected by ELISAs. ${ }^{22}$

\section{Statistical analysis}

The percentage of patients positive for autoantibodies, ACR criteria, concurrent autoimmune diseases or symptoms or medication usage was compared between Native Americans and each of the other groups (African-American, European American and Hispanic) by Fisher's exact test. Distributions such as age of disease onset were analysed using non-parametric, unpaired Mann-Whitney test. Univariate analyses were performed in GraphPad Prism V.7.02. A multivariate analysis was performed with backward model selection by Bayesian information criterion using the function 'step' in R (settings: upper model=race+region, lower model=race) to evaluate race effect with region as a covariate in the model. ${ }^{26} 27$

\section{RESULTS}

Native Americans have earlier SLE onset compared with other racial groups

Self-reported Native American patients with SLE ( $\mathrm{n}=268$ ) in the LFRR cohort ranged from 12 to 65 years of age. Age of onset was calculated based on when the participant first met ACR classification criteria compared with date of birth. Native Americans had a significantly lower mean age of disease onset $(29.89 \pm 12.3$ years) compared with European Americans $(32.02 \pm 12.87$ years; $\mathrm{P}=0.0157)$, and similar age of onset compared with African-Americans (30.83 \pm 11.19 years) and Hispanics $(27.77 \pm 11.66$ years) (table 1). Furthermore, a significantly higher proportion of Native American participants (26\%) reached SLE classification in the first two decades of life compared with African-Americans $(19 \%, \mathrm{P}=0.0050)$, a higher percentage compared with European American (21\%) and similar to Hispanic patients (28\%) (figure 1A). Racial and ethnic differences in the age of onset were not influenced by region of residence (online supplementary table 1 ).

High autoantibody titres and unidentified autospecificities are common among Native American patients with SLE

A hallmark feature of SLE is the presence of antinuclear autoantibodies. The rate of ANA positivity by IIF in Native American patients with SLE (97\%) was significantly higher than the rate in European American (91\%; $\mathrm{P}=0.0004)$ or Hispanic (92\%; $\mathrm{P}=0.0257$ ) patients with SLE, but similar to the rate in African-American patients with SLE (97\%; $\mathrm{P}=0.8503$ ) (table 2). The percentage of patients with SLE with high ANA titres was also higher in Native Americans than European Americans $(\mathrm{P}<0.0001)$ and similar between Native American and African-American patients with SLE (figure 1B, 1:3240 and 1:9720).

In addition, the pattern of autoreactivity differed between Native American patients and other groups. Anti-dsDNA was observed in $34 \%$ of Native American patients with SLE, similar to the rate in African-American patients and significantly higher than in European American or Hispanic patients with SLE (table 2). Native 
Table 1 Patient demographics and classification information.

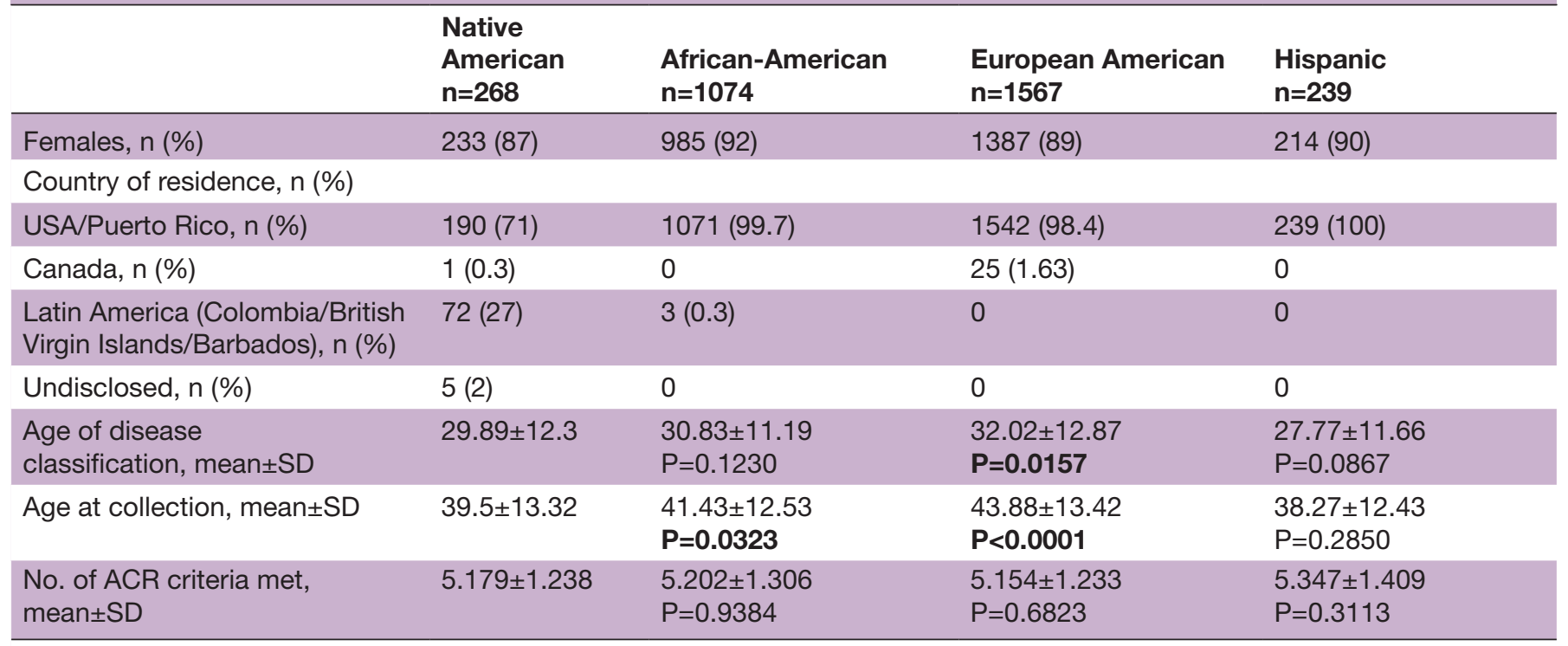

Demographics were collected by patient report. ACR classification criteria were extracted by standardised, protocol-directed medical record extraction for all individuals. Age of disease onset, age at collection and average ACR criteria met were analysed using non-parametric, unpaired Mann-Whitney test. Bold $P$ values are significant compared with the Native American group.

ACR, American College of Rheumatology.

Americans had significantly higher levels of anti-Sm (6\%) compared with European Americans (2\%; $\mathrm{P}=0.0021)$ but lower levels compared with African-Americans (13\%, $\mathrm{P}=0.0002)$. Additionally, Native Americans had significantly higher levels of anti-nRNP (16\%) compared with European Americans (9\%; $\mathrm{P}=0.0008)$ but lower levels compared with African-Americans (37\%; $\mathrm{P}<0.0001)$. Native American patients also had high rates of anti-Ro/ SSA (27\%) compared with European American patients (17\%; $\mathrm{P}=0.0002)$. Levels of aCL IgG were observed to be significantly higher in Native Americans (35\%) compared with European Americans (27\%; P=0.0190), and aCL IgM levels were observed to be significantly higher in Native Americans (11\%) compared with African-Americans (5\%; $\mathrm{P}=0.0011$ ). Additionally, Native American patients with SLE were the most likely to have precipitin levels of unidentified autoantibody specificities; the rate of unidentified specificities was at least 1.7 -fold higher in Native Americans than in any other group (Native American $41 \%$ vs African-American: 24\%, P=0.0006; European American: 17\%, $\mathrm{P}<0.0001$; Hispanic: 23\%, $\mathrm{P}=0.005)$. Racial and ethnic differences in ANA titres and autoantibody rates were not influenced by region of residence (online supplementary table 2 ).

Native American patients with SLE exhibit similar ACR clinical criteria to European American and Hispanic patients with SLE Average ACR scores were similar between all racial groups (table 1). However, some individual criteria were significantly more common among Native American patients than African-American patients, including malar rash $(59 \%$ vs $45 \%$; $\mathrm{P}=0.0001)$, photosensitivity ( $54 \%$ vs $38 \% ; \mathrm{P}<0.0001)$ and oral ulcers $(44 \%$ vs $36 \% ; \mathrm{P}=0.0293)$. Additionally, Native American patients compared with
European American patients had higher rates of proteinuria $(46 \%$ vs $35 \% ; \mathrm{P}=0.001)$ and haemolytic anaemia (20\% vs $10 \% ; \mathrm{P}<0.0001$ ) (table 3 ). Racial and ethnic differences in ACR criteria were not influenced by region of residence (online supplementary table 3 ).

\section{Select concurrent autoimmune rheumatic diseases or symptoms vary between Native American patients with SLE and other groups of patients with SLE}

Concurrent autoimmune rheumatic diseases or associated symptoms (Raynaud's syndrome, interstitial lung disease, sicca symptoms, Sjögren's syndrome, systemic sclerosis and myalgias) were observed in $71 \%$ of Native American patients with SLE, compared with $69 \%$ of African-American $(\mathrm{P}=0.5064), 74 \%$ of European American $(\mathrm{P}=0.2950)$ and $74 \%$ of Hispanic $(\mathrm{P}=0.7674)$ patients with SLE in this study. Rates of individual conditions varied between groups (table 4). Native American patients with SLE had significantly higher rates of interstitial lung disease (1\%) and systemic sclerosis (3\%) than African-American or European American patients with SLE, and lower rates of myalgias (44\%) compared with African-American patients (table 4). Rates of myalgia were also lower in Native American patients with SLE compared with Hispanic patients with SLE (table 4). However, multivariate analysis showed that Latin American residence influenced this comparison (online supplementary table 1), with myalgias present in 55\% (104/190) of Native American patients from the USA and Puerto Rico and 27\% (17/72) of their counterparts from Latin America. Raynaud's phenomenon was more common in Native Americans (34\%) compared with African-Americans (27\%; $\mathrm{P}=0.0186)$. Secondary Sjögren's syndrome was more common in Native American patients with SLE 

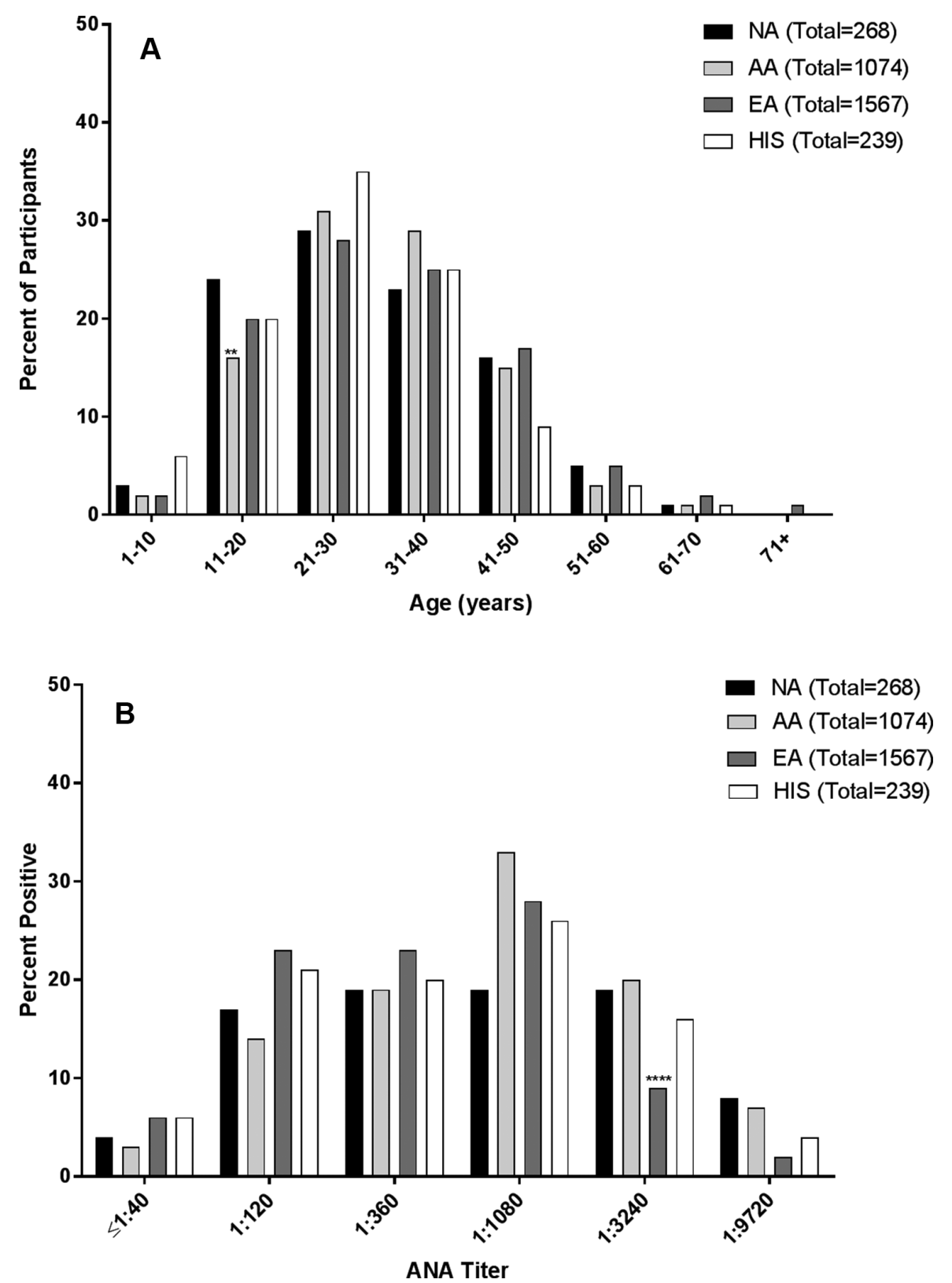

Figure 1 Age and antinuclear autoantibody (ANA) titres of LFRR patients at time of SLE classification. (A) Age at SLE classification was determined by medical record review. Native American (NA) patients with SLE in this collection were more likely to be classified with SLE in their paediatric years ( $<20$ years of age; $26 \%, n=71 / 268)$ compared with African-Americans (AA; $n=200 / 1074,19 \%, P=0.0050$ ) and similar to European Americans (EA; 21\%, $n=333 / 1567$ ) and Hispanics (HIS; 26\%, $n=63 / 239$ ). Significance was determined by Fisher's exact test: ${ }^{*} P<0.05,{ }^{* *} P<0.01,{ }^{* * *} P<0.001,{ }^{* * \star *} P<0.0001$. (B) Patients were screened for ANA by indirect immunofluorescence with Hep-2 cells. Thirty-one per cent $(n=85 / 268)$ of NA patients with SLE had titres $\geq 1: 3240$, similar to $A A(33 \%, n=363 / 1074)$ and HIS $(25 \%, n=60 / 239)$ and significantly higher than $E A(13 \%, n=218 / 1567$; $\mathrm{P}<0.0001)$. Significance was determined by Fisher's exact test: ${ }^{\star} \mathrm{P}<0.05,{ }^{* \star} \mathrm{P}<0.01,{ }^{* \star \star} \mathrm{P}<0.001,{ }^{* \star \star *} \mathrm{P}<0.0001$.

$(15 \%)$ than in African-Americans $(8 \% ; \mathrm{P}=0.0006)$ but less common than in European Americans (22\%; $\mathrm{P}=0.0140)$.

Native American patients with SLE are more likely to use methotrexate or mycophenolate mofetil compared with other patients with lupus and less likely to use hydroxychloroquine (HCQ)

HCQ an antimalarial drug, remains the cornerstone of SLE treatment and is recommended for all patients with SLE without a contraindication. ${ }^{28}$ However, HCQ was used less frequently for Native American patients with SLE $(68 \%)$ than for patients with SLE of other racial groups (African-American: 74\%, $\mathrm{P}=0.0308$; European American: $79 \%, \mathrm{P}=0.0001$; and Hispanics: $77 \%$, $\mathrm{P}=0.0173$ ) (figure 2). However, Latin American residence was again a significant covariate when comparing hydroxychloroquine use between Native American and Hispanic patients with SLE (online supplementary table 4), with 
Table 2 Autoantibody specificities in Native American patients with SLE compared with other ethnicities

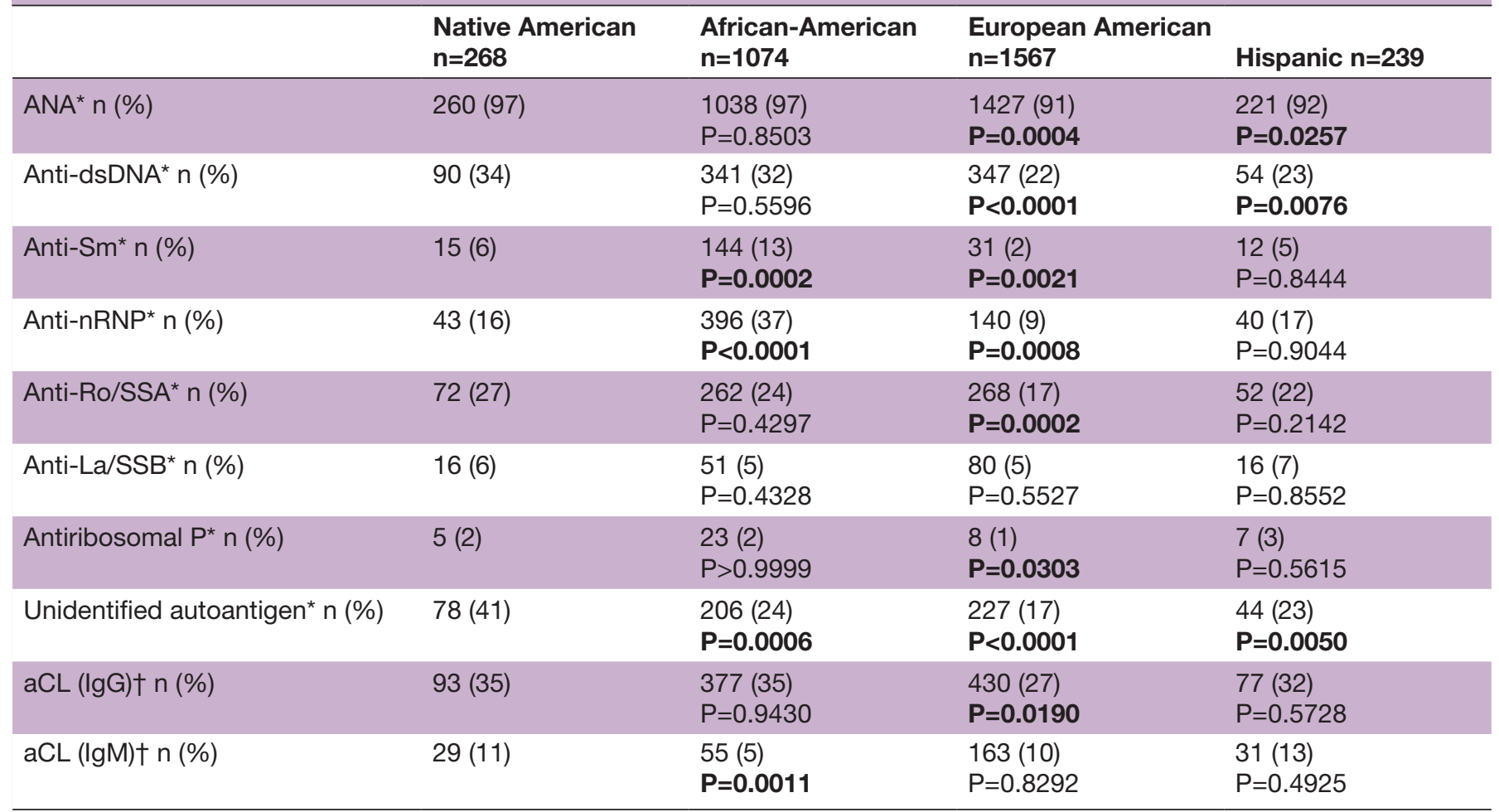

Number and percentage of patients positive, and $\mathrm{P}$ values are shown. Differences in autoantibody specificities were analysed using Fisher's exact test. Bold $P$ values are significant compared with the Native American group.

*These autoantibody specificities were determined by IIF.

†These autoantibody specificities were determined by ELISA.

aCL, anticardiolipin; dsDNA, double-stranded DNA; IIF, indirect immunofluorescence; SLE, systemic lupus erythematosus.

HCQ use in $82 \%(155 / 190)$ of Native American patients from the USA and Puerto Rico and 32\% (23/72) of their counterparts from Latin America. In contrast, methotrexate was used more commonly for Native American patients with SLE (28\%) than for African-American and Hispanic patients $(18 \%, \mathrm{P}=0.0006$ and $14 \%, \mathrm{P}=0.0003)$, and azathioprine was used more commonly for Native American (38\%) compared with European American patients $(30 \%, \mathrm{P}=0.0105)$. Cyclophosphamide was used similarly for Native American (22\%), African-American $(27 \%)$ and European American (22\%) patients and more commonly for Hispanic patients $(32 \%, \mathrm{P}=0.0208)$. Mycophenolate mofetil use was the same for Native Americans (26\%) and African-Americans (24\%) and significantly greater than European Americans $(17 \%, \mathrm{P}=0.0012)$ and Hispanics $(11 \%, \mathrm{P}<0.0001)$.

\section{DISCUSSION}

Several studies have demonstrated that the incidence and prevalence of SLE in Native American populations is comparable with African-American populations and higher than European American populations. ${ }^{10}{ }^{11}$ Native American patients with SLE often have earlier age of onset, greater accumulation of damage and organ involvement compared with other patients with SLE in the surrounding population. ${ }^{11} 29$ The current study focused on identifying unique clinical features associated with
SLE in Native American patients, as well as evaluating differences in autospecificities and treatment histories of Native American patients. We compared these findings to those of African-American, European American and Hispanic patients with SLE.

The age at which SLE is first classified in the different racial groups of this study is heterogeneous in several ways and supports the idea that there are population-specific differences in SLE pathogenesis. ${ }^{6}$ We report that Native Americans are often younger when they meet SLE classification, with a striking percentage of Native Americans reaching SLE classification in the first two decades of life $(26 \%)$. Our results differ from those in a population-based registry study examining the incidence and prevalence of SLE in Native Americans from the USA, which found an average age of 39.2 years for prevalent cases and 45.5 years for incident cases. Because our Native American cohort includes a large number $(n=72)$ of individuals from Latin America, and it has been shown that individuals from Latin America tend to develop SLE at an earlier age, we considered that the difference in the age of onset between this study and ours may be explained by the differences in region of residence. However, we observed through multivariate analysis that the region of residence did not influence the age of onset (online supplementary table 1). ${ }^{30}$ Another possible explanation is that our study includes individuals recruited into the 
Table 3 Percentage of patients with SLE satisfying ACR criteria by self-reported race/ethnicity

\begin{tabular}{|c|c|c|c|c|}
\hline & $\begin{array}{l}\text { Native American } \\
\mathrm{n}=268\end{array}$ & $\begin{array}{l}\text { African-American } \\
\mathrm{n}=1074\end{array}$ & $\begin{array}{l}\text { European American } \\
n=1567\end{array}$ & $\begin{array}{l}\text { Hispanic } \\
\mathrm{n}=239\end{array}$ \\
\hline Malar rash, n (\%) & $158(59)$ & $\begin{array}{l}491(45) \\
P=0.0001\end{array}$ & $\begin{array}{l}1043(66) \\
P=0.018\end{array}$ & $\begin{array}{l}150(62) \\
P=0.4126\end{array}$ \\
\hline Discoid rash, n (\%) & $65(24)$ & $\begin{array}{l}411(38) \\
P<0.0001\end{array}$ & $\begin{array}{l}408(26) \\
P=0.5969\end{array}$ & $\begin{array}{l}53(22) \\
P=0.6\end{array}$ \\
\hline Photosensitivity, n (\%) & $146(54)$ & $\begin{array}{l}418(38) \\
P<0.0001\end{array}$ & $\begin{array}{l}946(60) \\
P=0.0799\end{array}$ & $\begin{array}{l}121(50) \\
P=0.4228\end{array}$ \\
\hline Oral ulcers, n (\%) & $117(44)$ & $\begin{array}{l}391(36) \\
P=0.0293\end{array}$ & $\begin{array}{l}716(45) \\
P=0.5507\end{array}$ & $\begin{array}{l}115(48) \\
P=0.327\end{array}$ \\
\hline Arthritis, n (\%) & $239(89)$ & $\begin{array}{l}984(91) \\
P=0.2292\end{array}$ & $\begin{array}{l}1447(92) \\
P=0.0896\end{array}$ & $\begin{array}{l}219(91) \\
P=0.3703\end{array}$ \\
\hline Pericarditis, n (\%) & $60(22)$ & $\begin{array}{l}326(30) \\
P=0.0103\end{array}$ & $\begin{array}{l}332(21) \\
P=0.6868\end{array}$ & $\begin{array}{l}67(28) \\
P=0.1516\end{array}$ \\
\hline Pleuritis, n (\%) & $130(49)$ & $\begin{array}{l}536(49) \\
P=0.7328\end{array}$ & $\begin{array}{l}783(49) \\
P=0.6918\end{array}$ & $\begin{array}{l}108(45) \\
P=0.4765\end{array}$ \\
\hline Proteinuria, n (\%) & $123(46)$ & $\begin{array}{l}623(58) \\
P=0.0004\end{array}$ & $\begin{array}{l}552(35) \\
P=0.001\end{array}$ & $\begin{array}{l}137(57) \\
P=0.0126\end{array}$ \\
\hline Cellular casts, n (\%) & $30(11)$ & $\begin{array}{l}221(20) \\
P=0.0003\end{array}$ & $\begin{array}{l}235(14) \\
P=0.11\end{array}$ & $\begin{array}{l}51(21) \\
P=0.0023\end{array}$ \\
\hline Seizures, n (\%) & $31(12)$ & $\begin{array}{l}174(16) \\
P=0.0709\end{array}$ & $\begin{array}{l}231(14) \\
P=0.1863\end{array}$ & $\begin{array}{l}36(15) \\
P=0.2934\end{array}$ \\
\hline Psychosis, n (\%) & $25(9)$ & $\begin{array}{l}122(11) \\
P=0.3826\end{array}$ & $\begin{array}{l}104(6) \\
P=0.1203\end{array}$ & $\begin{array}{l}24(10) \\
P=0.8805\end{array}$ \\
\hline Haemolytic anaemia, n (\%) & $53(20)$ & $\begin{array}{l}196(18) \\
P=0.5982\end{array}$ & $\begin{array}{l}168(10) \\
P<0.0001\end{array}$ & $\begin{array}{l}43(17) \\
P=0.6504\end{array}$ \\
\hline Leucopaenia, n (\%) & $113(42)$ & $\begin{array}{l}619(57) \\
P<0.0001\end{array}$ & $\begin{array}{l}620(39) \\
P=0.4191\end{array}$ & $\begin{array}{l}94(39) \\
P=0.5277\end{array}$ \\
\hline Lymphopaenia, n (\%) & $137(51)$ & $\begin{array}{l}614(57) \\
P=0.0854\end{array}$ & $\begin{array}{l}833(53) \\
P=0.5516\end{array}$ & $\begin{array}{l}140(58) \\
P=0.1077\end{array}$ \\
\hline
\end{tabular}

Bold $P$ values are significant by Fisher's exact test $(P \leq 0.05)$ compared with Native American population.

ACR, American College of Rheumatology; SLE, systemic lupus erythematosus.

LFRR, which contains multiplex families that may have a greater chance of being diagnosed at an earlier age compared with individual clinical cases within the Indian Health Service (IHS). The LFRR also included patients with SLE who received their healthcare in a number of different systems outside the IHS and had referring paediatric rheumatologists. These results as well as the noted clinical differences underscore the importance of early vigilance, careful history-taking and clinical follow-up for Native American paediatric patients with rheumatic disease. For many Native Americans, early diagnosis with continued monitoring is difficult to obtain due to confusing autoantibody results and restricted access to healthcare specialists. ${ }^{31}$ These disparities thus potentially contribute to delays in diagnosis and clinical monitoring, potentially resulting in increased damage accrual and worse outcomes some in Native American patients.

We observed that Native American patients with SLE are more likely to have high ANA titres compared with patients of other races. More importantly, Native American patients with SLE are more likely to have unidentified autoantibody specificities. These observations underscore the need to identify and confirm unique, novel autoantigens that may be associated with the development of SLE in Native Americans. This would allow for a more tailored and inclusive diagnosis, monitoring and treatment, ideally leading to more favourable outcomes and less disease-associated morbidity and mortality.

The Native American patients with SLE in our study had higher rates of select concurrent autoimmune rheumatic diseases or disease symptoms than African-American and European American patients with SLE, but similar rates were observed between Native American and Hispanic patients with SLE. These observations support the findings of others that Native Americans with SLE have a more complex disease course and less favourable outcomes. ${ }^{7}$ Although Native Americans developed SLE earlier and had expanded clinical manifestations, Native American patients with SLE were the least likely to use HCQ, a fundamental therapeutic used for SLE. ${ }^{32}$ However, more of the Native American patients with SLE were treated with methotrexate and mycophenolate 
Table 4 Concurrent autoimmune diseases or symptoms in Native American patients compared with patients of other races/ ethnicities

\begin{tabular}{|c|c|c|c|c|}
\hline & $\begin{array}{l}\text { Native American } \\
\mathrm{n}=268\end{array}$ & $\begin{array}{l}\text { African-American } \\
n=1074\end{array}$ & $\begin{array}{l}\text { European American } \\
\mathrm{n}=1567\end{array}$ & $\begin{array}{l}\text { Hispanic } \\
\mathrm{n}=239\end{array}$ \\
\hline $\begin{array}{l}\text { Raynaud's syndrome, } \\
\text { n (\%) }\end{array}$ & $92(34)$ & $\begin{array}{l}288(27) \\
P=0.0186\end{array}$ & $\begin{array}{l}559(36) \\
P=0.7298\end{array}$ & $\begin{array}{l}67(28) \\
P=0.1503\end{array}$ \\
\hline ILD, n (\%) & $4(1)$ & $\begin{array}{l}1(<1) \\
P=0.0066\end{array}$ & $\begin{array}{l}4(<1) \\
P=0.0192\end{array}$ & $\begin{array}{l}1(<1) \\
P=0.3766\end{array}$ \\
\hline Sicca, n (\%) & $26(10)$ & $\begin{array}{l}77(7) \\
P=0.1604\end{array}$ & $\begin{array}{l}223(14) \\
P=0.0530\end{array}$ & $\begin{array}{l}19(8) \\
P=0.5338\end{array}$ \\
\hline $\begin{array}{l}\text { Sjögren's syndrome, n } \\
(\%)\end{array}$ & $40(15)$ & $\begin{array}{l}84(8) \\
P=0.0006\end{array}$ & $\begin{array}{l}337(22) \\
P=0.0140\end{array}$ & $\begin{array}{l}35(15) \\
P>0.9999\end{array}$ \\
\hline $\begin{array}{l}\text { Systemic sclerosis, } \\
\text { n (\%) }\end{array}$ & $7(3)$ & $\begin{array}{l}8(1) \\
P=0.0173\end{array}$ & $\begin{array}{l}3(<1) \\
P=0.0001\end{array}$ & $\begin{array}{l}10(4) \\
P=0.3373\end{array}$ \\
\hline Myalgias, n (\%) & $119(44)$ & $\begin{array}{l}557(52) \\
P=0.0341\end{array}$ & $\begin{array}{l}772(49) \\
P=0.1461\end{array}$ & $\begin{array}{l}134(56) \\
P=0.0099\end{array}$ \\
\hline
\end{tabular}

Number and percentage of patients with the comorbidity, and $\mathrm{P}$ values are shown. Differences in comorbidities were analysed using Fisher's exact test. Bold $P$ values are significant compared with the Native American group.

ILD, interstitial lung disease.

mofetil. The reason for the reduced rate of HCQ use and increased use of methotrexate and mycophenolate mofetil is not clear. However, these differences may be explained in part by concerns about retinopathies from comorbidities such as diabetes or by lack of access to specialised ocular monitoring. ${ }^{33}$ In addition, patients with organ-threatening disease requiring more aggressive treatments such as mycophenolate mofetil may not take concurrent HCQ. In our study, 27\% $(n=72)$ of Native
Americans were from Latin America, where approaches to treatment may be different. This idea was supported by our multivariate analysis, which showed that the use of HCQ was significantly affected by region of residence for Native American patients with SLE (online supplementary table 4 ).

Significant differences in age of onset, as well as clinical manifestations of disease, are observed in Native American SLE subjects in this study as compared with subjects

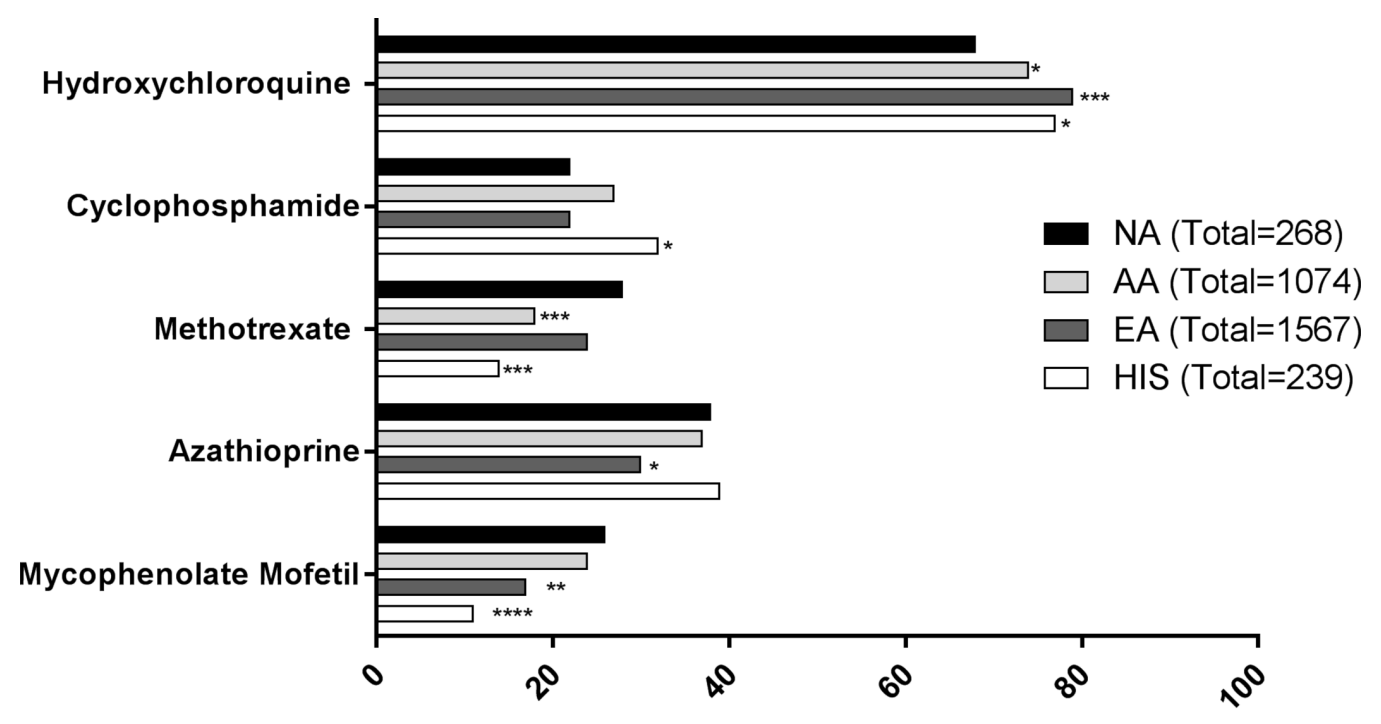

Percent Reporting Use

Figure 2 Use of disease-modifying antirheumatic drugs in Native Americans compared with other racial subgroups. Hydroxychloroquine, cyclophosphamide, methotrexate, azathioprine or mycophenolate mofetil use was determined from patient self-reporting or review of medical records. Significantly fewer Native Americans (NA) had used hydroxychloroquine (71\%, $\mathrm{n}=190 / 268$ ) compared with all other groups (African-American (AA): 79\%, $n=853 / 1074, \mathrm{P}=0.0040$; European American (EA): 83\%, $n=1305 / 1567, \mathrm{P}<0.0001$; Hispanic (HIS): 82\%, $\mathrm{n}=195 / 239, \mathrm{P}=0.0050)$. In contrast, significantly more NAs (30\%, $\mathrm{n}=81 / 268)$ reported using methotrexate compared with AAs (20\%, $n=211 / 1074, P=0.0003)$ and HIS (15\%, 36/239, $P<0.0001)$. Additionally, significantly more NAs $(26 \%, n=71 / 268)$ reported using mycophenolate mofetil compared with EAs (19\%, $n=290 / 1567)$ and HIS (13\%, $n=30 / 239)$. Significance was determined by Fisher's exact test: ${ }^{\star} \mathrm{P}<0.05,{ }^{\star \star} \mathrm{P}<0.01,{ }^{\star \star \star} \mathrm{P}<0.001,{ }^{\star \star \star *} \mathrm{P}<0.0001$. 
of other racial/ethnic groups. These findings underscore the need for additional studies aimed at identifying molecular markers of disease that can aid earlier classification in Native American populations. Furthermore, the differences observed in the Native American subjects with SLE need to be considered in ongoing training of primary care clinicians so that they are more prepared to recognise, diagnose and treat Native American patients. Additionally, as this analysis focused on self-reported demographics, a genetic approach as related to ethnicity could help ascertain population-specific differences between groups of Native American patients.

\section{Author affiliations}

${ }^{1}$ Department of Arthritis and Clinical Immunology, Oklahoma Medical Research

Foundation, Oklahoma City, Oklahoma, USA

${ }^{2}$ Oklahoma State University Health Sciences Center, Tulsa, Oklahoma, USA

${ }^{3}$ Division of Rheumatology, Cedars-Sinai Medical Center, Los Angeles, California, USA

${ }^{4}$ Center for Autoimmune Diseases Research (CREA), School of Medicine and Health Sciences, Universidad del Rosario, Bogotá, Colombia

${ }^{5}$ Artmedica IPS, Bogotá, Colombia

${ }^{6}$ Jacobs School of Medicine and Biomedical Sciences, University at Buffalo, Buffalo, New York, USA

${ }^{7}$ Center for Autoimmune Genomics and Etiology (CAGE), Cincinnati Children's Hospital Medical Center, Cincinnati, Ohio, USA

${ }^{8}$ US Department of Veterans Affairs Medical Center, Cincinnati, Ohio, USA ${ }^{9}$ Department of Medicine and Pathology, University of Oklahoma Health Sciences Center, Oklahoma City, Oklahoma, USA

Acknowledgements The authors would like to thank Susan Macwana and the OMRF Biorepository personnel. We would also like to thank Wade DeJager and Krista Bean for technical assistance and data acquisition, and Hua Chen for statistical assistance. Additionally, we would like to thank the LFRR and all referring physicians, clinical personnel and LFRR participants.

Contributors JMK, CJG, JBH and JAJ designed the study. All authors participated in data acquisition, analysis and/or interpretation. All authors assisted with the development of the manuscript and approved the final version to be published. JAJ had final responsibility for the decision to submit for publication.

Funding Research reported in this publication was supported by grants from the National Institutes of Health, the Indian Health Service and the US Department of Veterans Affairs (U26IHS0088, U54GM104938, P30GM103510, P30AR053483, U19AI082714, U01Al101934, U01All30830, R01Al024717, U01HG008666 and I01BX001834). Research reported herein was supported by an Institutional Development Award (IDeA) from the National Institute of General Medical Sciences of the National Institutes of Health.

Disclaimer The study sponsors had no role in the study design; in the collection, analysis and interpretation of the data; in the writing of the report; nor in the decision to submit the paper for publication. The content is solely the responsibility of the authors and does not necessarily represent the official views of the National Institutes of Health, the Indian Health Service, or the United States Government.

Competing interests AR reports personal fees from ThermoFisher for talks regarding diagnosis and classification of Sjögren's syndrome and the different autoantibody testing platforms.

Patient consent Not required.

Ethics approval Research was approved by the Institutional Review Boards of the Oklahoma Medical Research Foundation and the University of Oklahoma Health Sciences Center.

Provenance and peer review Not commissioned; externally peer reviewed. Data sharing statement All relevant data for this study are being published.

Open Access This is an Open Access article distributed in accordance with the Creative Commons Attribution Non Commercial (CC BY-NC 4.0) license, which permits others to distribute, remix, adapt, build upon this work non-commercially, and license their derivative works on different terms, provided the original work is properly cited and the use is non-commercial. See: http://creativecommons.org/ licenses/by-nc/4.0/

(C) Article author(s) (or their employer(s) unless otherwise stated in the text of the article) 2018. All rights reserved. No commercial use is permitted unless otherwise expressly granted.

\section{REFERENCES}

1. Manuel F, Ugarte-Gil GJP-E, Alarcón GS, et al. Epidemiology. Tsokos GC, ed. Systemic Lupus Erythematosus; Basic, Applied and Clinical Aspects. Boston, MA, USA: Elsevier Inc, 2016:15-21.

2. Munroe ME, Vista ES, Guthridge JM, et al. Proinflammatory adaptive cytokine and shed tumor necrosis factor receptor levels are elevated preceding systemic lupus erythematosus disease flare. Arthritis Rheumatol 2014;66:1888-99.

3. Susan Malkiel BD. Anti-DNA antibodies. Tsokos GC, ed. Systemic Lupus Erythematosus; Basic, Applied and Clinical Aspects. Bostan, MA, USA: Elsevier Inc, 2016:207-11.

4. Lu R, Munroe ME, Guthridge JM, et al. Dysregulation of innate and adaptive serum mediators precedes systemic lupus erythematosus classification and improves prognostic accuracy of autoantibodies. $J$ Autoimmun 2016;74:182-93.

5. Worrall JG, Snaith ML, Batchelor JR, et al. SLE: a rheumatological view. Analysis of the clinical features, serology and immunogenetics of 100 SLE patients during long-term follow-up. Q J Med 1990;74:319-30.

6. Kaslow RA, Masi AT. Age, sex, and race effects on mortality from systemic lupus erythematosus in the United States. Arthritis Rheum 1978;21:473-9.

7. Gómez-Puerta JA, Barbhaiya M, Guan H, et al. Racial/Ethnic variation in all-cause mortality among United States medicaid recipients with systemic lupus erythematosus: a Hispanic and asian paradox. Arthritis Rheumatol 2015;67:752-60.

8. Bombardier C, Gladman DD, Urowitz MB, et al. Derivation of the SLEDAI. A disease activity index for lupus patients. The Committee on Prognosis Studies in SLE. Arthritis Rheum 1992;35:630-40.

9. Atkins C, Reuffel L, Roddy J, et al. Rheumatic disease in the NuuChah-Nulth native Indians of the Pacific Northwest. J Rheumatol 1988;15:684-90.

10. Ferucci ED, Johnston JM, Gaddy JR, et al. Prevalence and incidence of systemic lupus erythematosus in a population-based registry of American Indian and Alaska Native people, 2007-2009. Arthritis Rheumatol 2014;66:2494-502.

11. Peschken CA, Esdaile JM. Rheumatic diseases in North America's indigenous peoples. Semin Arthritis Rheum 1999;28:368-91.

12. Peschken CA, Esdaile JM. Systemic lupus erythematosus in North American Indians: a population based study. J Rheumatol 2000;27:1884-91.

13. Ferucci ED, Johnston JM, Gordon C, et al. Prevalence of Mixed Connective Tissue Disease in a Population-Based Registry of American Indian/Alaska Native People in 2007. Arthritis Care Res 2017:69:1271-5.

14. Cheema GS, QuismorioFP. Interstitial lung disease in systemic lupus erythematosus. Curr Opin Pulm Med 2000;6:424-9.

15. Samantha A, Rachel A, Duckett P. Health coverage and care for American Indians and Alaska Natives. Menlo Park, California: Andy Schneider, Kitty Marx, Geoffrey Roth, Ralph Foquera, and Doneg McDonough: Kaiser Family Foundation, 2013.

16. Barnabe C, Jones CA, Bernatsky S, et al. Inflammatory Arthritis Prevalence and Health Services Use in the First Nations and NonFirst Nations Populations of Alberta, Canada. Arthritis Care Res 2017;69:467-74

17. Gillis JZ, Yazdany J, Trupin L, et al. Medicaid and access to care among persons with systemic lupus erythematosus. Arthritis Rheum 2007;57:601-7.

18. Wong ST, Kao C, Crouch JA, et al. Rural American Indian Medicaid health care services use and health care costs in California. Am J Public Health 2006;96:363-70.

19. Gaddy JR, Vista ES, Robertson JM, et al. Rheumatic disease among Oklahoma tribal populations: a cross-sectional study. J Rheumatol 2012;39:1934-41.

20. Kuwana M, Kaburaki J, Arnett FC, et al. Influence of ethnic background on clinical and serologic features in patients with systemic sclerosis and anti-DNA topoisomerase I antibody. Arthritis Rheum 1999;42:465-74.

21. Scofield RH, Fogle M, Rhoades ER, et al. Rheumatoid arthritis in a United States Public Health Service Hospital in Oklahoma: serologic manifestations in rheumatoid arthritis vary among tribal groups. Arthritis Rheum 1996;39:283-6. 
22. Rasmussen A, Sevier S, Kelly JA, et al. The lupus family registry and repository. Rheumatology 2011;50:47-59.

23. Hochberg MC. Updating the American college of rheumatology revised criteria for the classification of systemic lupus erythematosus. Arthritis Rheum 1997;40:1725.

24. Tan EM, Cohen AS, Fries JF, et al. The 1982 revised criteria for the classification of systemic lupus erythematosus. Arthritis Rheum 1982;25:1271-7.

25. Swaak AJ, Huysen V, Nossent JC, et al. Antinuclear antibody profiles in relation to specific disease manifestations of systemic lupus erythematosus. Clin Rheumatol 1990;9:82-95.

26. Hastie TJ, Pregibon D. Generalized linear models. In: Chambers JM, Hastie TJ, eds. Statistical Models in S: Wadsworth \& Brooks/Cole, 1992.

27. Venables WN, Ripley BD. Modern Applied Statistics with S. 4 ed. New York: Springer, 2002.

28. Paz Z. Value of Antimalarial Drugs in the Treatment of Lupus.. Tsokos GC, ed. Systemic Lupus Erythematosus Basic, Applied and Clinical
Aspects. Harvard Medical School, Boston, MA, USA: Elsevier Inc., 2016:515-20.

29. Barnabe C, Joseph L, Belisle P, et al. Prevalence of systemic lupus erythematosus and systemic sclerosis in the First Nations population of Alberta, Canada. Arthritis Care Res 2012;64:138-43.

30. Pons-Estel BA, Catoggio LJ, Cardiel MH, et al. The GLADEL multinational Latin American prospective inception cohort of 1,214 patients with systemic lupus erythematosus: ethnic and disease heterogeneity among "Hispanics". Medicine 2004;83:1-17.

31. Sarche M, Spicer P. Poverty and health disparities for American Indian and Alaska Native children: current knowledge and future prospects. Ann N Y Acad Sci 2008;1136:126-36.

32. Alarcón GS, McGwin G, Bertoli AM, et al. Effect of hydroxychloroquine on the survival of patients with systemic lupus erythematosus: data from LUMINA, a multiethnic US cohort (LUMINA L). Ann Rheum Dis 2007;66:1168-72.

33. Spanakis EK, Golden SH. Race/ethnic difference in diabetes and diabetic complications. Curr Diab Rep 2013;13:814-23. 